\title{
Metadados de negócio: representação da informação dos processos de trabalho
}

\author{
Business metadata: Representation of \\ business processes' information
}

Mariana Baptista BRANDT ${ }^{1}$ (D) 0000-0001-8119-7527
Silvana Aparecida Borsetti Gregorio VIDOTTI ${ }^{1}$ iD 0000-0002-4216-0374

\section{Resumo}

Metadados são considerados elementos fundamentais na Ciência da Informação e suas características, aplicações e tipologias vêm sendo bastante estudados pelos pesquisadores da área, principalmente a partir dos anos 2000. Esta pesquisa busca trazer para a Ciência da Informação e propor o estudo de um novo tipo de metadado, o chamado metadado de negócio. Metadados de negócio são o contexto do negócio, na linguagem dos atores do negócio, por trás dos dados e podem ser encontrados em qualquer processo de trabalho nos diferentes setores das diversas instituições. Considerando a falta de literatura brasileira sobre este tipo de metadado na Ciência da Informação, objetiva-se trazer o conceito, aplicações, exemplos e estudos sobre metadados de negócio, por meio de pesquisa bibliográfica. A pesquisa é de natureza teórica e conceitual, caracterizando-se como pesquisa exploratória. Desse modo, observam-se nos metadados de negócio características bastante pertinentes aos conceitos e princípios da Ciência da Informação. Isso permite concluir que este conceito pode e deve ser inserido na área, principalmente nos estudos relacionados à Arquitetura da Informação, Sistemas de Informação e Recuperação da Informação.

Palavras-chave: Arquitetura da Informação. Informação corporativa. Metadados.

\begin{abstract}
Metadata are considered fundamental elements in Library and Information Science and its and its characteristics, applications and typologies is been studied extensively by researchers in the area, mainly since 2000. This article aims to bring a new typology of metadata to Brazilian Library and Information Science studies, the so-called business metadata. Business metadata are the business context behind data and can be found in any business process in the different sectors of diverse institutions. Considering the lack of literature about this kind of metadata in Library and Information Science, using literature research, this paper aims to bring its concept, applications, examples and studies about business metadata. This research is theoretical and conceptual nature, characterized as exploratory research. Business metadata could be observed as very pertinent to the concepts and principles of Library and Information Science, which allows concluding that this concept can and should be studied by the area, mainly in the studies related to Information Architecture, Information Systems and Information Retrieval.
\end{abstract}

Keywords: Information Architecture. Enterprise Information. Metadata.

\footnotetext{
1 Universidade Estadual Paulista Júlio de Mesquita Filho, Faculdade de Filosofia e Ciências, Departamento de Ciência da Informação. Av. Hygino Muzzi Filho, 737, Campus Universitário, 17525-900, Marilia, SP, Brasil. Correspondência para/Correspondence to: S.A.B.G. VIDOTTI. E-mail: <silvana.vidotti@unesp.br>.

Recebido em 30 de janeiro de 2018, versão final reapresentada em 1 de novembro de 2018 e aprovada em 5 de novembro de 2018.
}

Como citar este artigo/How to cite this article

Brandt, M.B.; Vidotti, S.A.B.G. Metadados de negócio: representação da informação dos processos de trabalho. Transinformação, v.31, e180006, 2019. http://dx.doi.org/10.1590/2318-0889201931e180006 


\section{Introdução}

Os metadados são elementos fundamentais para a representação e a recuperação da informação e podem ser considerados como conceito e área de estudo essenciais da Ciência da Informação (CI). Metadados são informações estruturadas que descrevem características dos recursos informacionais para diferentes propósitos, como identificação, gestão, descoberta, recuperação, interoperabilidade, descrição, entre outros. A literatura da área costuma classificar os metadados em cinco tipos básicos: administrativos, descritivos, preservação, técnicos e uso, os quais são utilizados para a descrição de recursos informacionais em geral.

Reflete-se, porém, sobre a necessidade de uma nova categoria de metadados, que possam ser utilizados para representar, registrar e descrever informações em uma granularidade mais fina que a do recurso informacional: a informação contida no recurso como item de representação e descrição próprias. Esses itens são as informações do negócio, dos processos de trabalho, dos serviços realizados no âmbito das instituições, e que não necessariamente estarão registradas e descritas nas representações dos recursos informacionais como um todo.

Para representar essas informações, observa-se a utilização do termo em inglês Business Metadata nas áreas de administração, gestão de dados, computação, arquitetura corporativa, e outras. Metadados de negócio são o contexto de negócio por trás dos dados, ou seja, o que as pessoas precisam saber sobre o que os dados representam. Portanto, servem para ajudar os gestores de negócio, ou seja, usuários não técnicos, no entendimento do dado (Sherman, 2006a; Inmon, O’Neil, Fryman, 2008). Segundo Inmon, O’Neil e Fryman (2008, p.12, tradução nossa), os metadados de negócio são "os metadados que são úteis para os gestores do negócio na condução do dia a dia de seu negócio" Os metadados de negócio auxiliam os desenvolvedores de sistemas de informação, já que trazem a informação estruturada, para serem inseridos nos sistemas de informação, bem como os gestores do negócio, pois, quando geridos de forma adequada, podem contribuir para a gestão da informação.

Este trabalho, de natureza teórica e conceitual, tem como objetivo estudar o termo Business Metadata e propor o termo em português "metadados de negócio" para esta que pode ser uma nova categoria para estudo e aplicação da temática de Metadados na Ciência da Informação. A proposta desta pesquisa é apresentar o termo "metadados de negócio" e seu conceito para a Cl e propor um olhar para o metadado: o de recurso informacional, que possui características e atributos próprios (meta-metadados) e pode ser representado e descrito assim, auxiliando a gestão e a governança da informação nas instituições.

\section{Procedimentos Metodológicos}

A pesquisa é de natureza teórica e conceitual, caracterizando-se como pesquisa bibliográfica e exploratória.

O desenvolvimento da pesquisa iniciou-se com a verificação do uso de termo "metadado de negócio" na Cl, nos artigos em língua portuguesa. Para isso, foi realizada busca pelos termos "metadados de negócio" e "metadado de negócio" na Base de Dados Referencias de Artigos de Periódicos em Ciências da Informação (BRAPCI), que reúne artigos de periódicos de Ciência da Informação. Como resultado, para ambas as buscas, no modo mais geral (pesquisa em todos os campos), não foram encontrados resultados, o que confirma a falta de utilização do termo na literatura brasileira de Cl. Além disso, uma pesquisa realizada no portal de periódicos da Coordenação de Aperfeiçoamento de Pessoal de Nível Superior (CAPES) também não encontrou resultados para os termos. As buscas foram feitas em novembro de 2017.

Dessa forma, confirmou-se a inexistência do termo "metadados de negócio"na literatura brasileira de Ciência da Informação. Assim, a pesquisa seguiu com a literatura de outras áreas para este conceito, com levantamento bibliográfico da literatura em inglês pelo termo Business Metadata e em português "metadado(s) de negócio". Assim, buscou-se identificar os principais aspectos do termo e trazer uma proposta de introdução deste conceito no Brasil, 
na Ciência da Informação, ressaltando sua interligação com conceitos da área e revelando possibilidades de estudo e aplicação.

\section{Metadados: definições, tipos e características}

Diferentes definições para o termo "metadado" foram propostas pelos autores da Ciência da Informação, Ciência da Computação e áreas afins, e o entendimento do conceito pode variar conforme a comunidade profissional envolvida em alguma atividade relacionada a recursos e sistemas de informação (Taylor, 2003; Alves, 2005; Castro e Santos, 2007; Gilliland, 2016). Para Taylor (2003, p.139, tradução nossa), o que as diferentes definições têm em comum é "[...] a noção de que metadado é informação estruturada que descreve atributos de recursos informacionais com o propósito de identificação, descoberta e, às vezes, administração". O termo foi popularizado a partir da necessidade de padronização dos recursos informacionais na internet, mas seu conceito já era bastante conhecido na Biblioteconomia, principalmente pelos profissionais da catalogação. Como constructos, metadados estão presentes, mesmo que, muitas vezes, de forma invisível, desde que a informação começou a ser organizada (Gilliland, 2016).

A definição literal "dado sobre dado" ainda é muito utilizada, porém, é considerada pouco específica, e, portanto, não satisfatória. Zeng e Qin (2008, p.7, tradução nossa) definem, de forma geral, que "[...] metadados encapsulam informações que descrevem qualquer documento ou objeto nos formatos digital e tradicional". A International Standard Organization (ISO) define metadados como dados que descrevem contexto, conteúdo e estrutura de registros e seu gerenciamento ao longo do tempo. Na definição encontrada na versão de 2005 do glossário da Dublin Core Metadata Initiative (DCMI), metadados são dados estruturados sobre dados e incluem dados associados a sistemas de informação ou objetos informacionais com o propósito de descrição, administração, requisito legal, funcionalidade técnica, uso e preservação. A organização afirma que:

Desde os anos 1990, "metadado" denota descrições, legíveis por máquina, de coisas, comumente no contexto da Web. Descrições estruturadas de metadados ajudam a encontrar recursos relevantes na massa de dados disponíveis online. Tudo pode ser descrito com metadados, de coleções de livros a ligas de futebol e coisas que você quer vender. Descrever tipos diferentes de recursos requer diferentes tipos de metadados e padrões de metadados (Ruhle; Baker; Johnston; 2011, s/p., tradução nossa).

Vários padrões de metadados foram propostos pelas diferentes comunidades e domínios do conhecimento. Um componente-chave nesses padrões é o conjunto de elementos, conhecido como "esquema", que define a estrutura e a semântica dos elementos. (Zeng, Qin, 2008). Os esquemas de metadados são formados por estrutura, sintaxe e semântica (Taylor, 2003). Como exemplo de padrões de metadados temos: Dublin Core, MARC, EAD, BIBFRAME, MODS, TEI, GILS, entre vários outros.

Entre as principais características dos metadados são destacadas interoperabilidade, flexibilidade e extensibilidade (Taylor, 2003; Zeng; Qin, 2008). Os metadados podem ser classificados por tipo, como descritivo, administrativo, técnico, estrutural, entre outros. Há diversas propostas de classificação dos metadados pelos autores. Taylor (2003) propõe as seguintes categorias: administrativos (com as subcategorias: preservação, direito e acesso e meta-metadado), estruturais e descritivos. Já Gilliland (2008) apresenta como tipos de metadado: administrativo, descritivo, de preservação, técnico e de uso. Segundo Zeng e Qin (2008), as categorias de metadados comumente aceitas pela comunidade de metadados são: administrativos, descritivos e estruturais. A National Information Standards Organization (NISO) considera, além desses, as linguagens de marcação como um tipo de metadado (National Information Standards Organization, 2004).

Um tipo de metadado definido e utilizado pela comunidade de gestão de dados, ciência da computação, arquitetura corporativa, inteligência de negócio e áreas correlatas, mas que ainda não é encontrado na literatura 
brasileira da Ciência da Informação, é o chamado Business metadata. Seu conceito e aplicações serão descritos na seção a seguir.

\section{Metadados de negócio}

Para esta pesquisa, optou-se pelo uso do termo em português "metadados de negócio" como tradução para business metadata. Seu conceito e características, trazidos das áreas que já o utilizam, serão discutidos nesta seção.

As informações de uma instituição estão geralmente armazenadas em sistemas de informação, automatizados ou não, e fazem parte - como insumo ou produto - dos processos de trabalho da instituição, conforme exemplificam os autores:

[...] organizações têm implementado sistemas para gerenciar praticamente todos os aspectos de seu negócio, incluindo sistemas de folha de pagamento, aplicações de contas a receber, sistemas de encomendas, gestão de campanhas de marketing, sistemas de recursos humanos, logística, aplicações de faturamento e até sistemas para rastrear a colocação de mobiliário de escritório e para férias de funcionários. (Marco, 2006, p.42, tradução nossa).

E:

Para apoiar os vários papéis como operação, monitoramento, controle e tomada de decisão, o processamento de dados e os sistemas de informação são ubíquos atualmente. Invariavelmente, organizações possuem uma multiplicidade de sistemas, cada um com seu escopo, propósito e funcionalidade específicos. (Sarda, 2001, p.4, tradução nossa).

Essas informações precisam ser mapeadas, registradas e gerenciadas para que sejam utilizadas de modo uniforme e consistente pelas áreas de negócio das instituições. Uma das formas de se realizar a gestão dessa informação institucional é pela identificação, registro e gerenciamento de metadados de negócio. Metadados de negócio podem ser definidos como informações importantes dos processos de trabalho, os quais fornecem o contexto do negócio, na linguagem do gestor do negócio, a respeito dos dados do negócio. Sua estruturação permite uma melhor gestão do próprio processo ou negócio ao qual pertence. Além disso, metadados de negócio podem fornecer insumo para a construção de sistemas de informação melhores, ou seja, que atendam efetivamente ao negócio e sejam capazes de gerar relatórios gerenciais com informações realmente necessárias para os gestores. O mapeamento de processos para captura de informações do negócio costuma ser realizado pelas áreas de computação e administração, porém, Sherman explica que:

O problema começa porque muito dos metadados de negócio contidos nos requisitos de negócio são usados para a construção de DW [datawarehouse] e planejamento de relatório, mas quando a TI implementa uma solução tecnológica, o que sobra do metadado de negócio é uma interpretação técnica armazenada nas ferramentas. A linguagem do negócio se perde. O principal desafio para os metadados de negócio é retomar o que foi perdido e traduzir para o metadado da ferramenta. (Sherman, 2006a, p.50, tradução nossa).

Segundo Inmon, Fryman e O’Neil (2008, p.1, tradução nossa):

Metadados de negócio existem desde que o homem criou o primeiro negócio. Nessa época, todos os metadados de negócio existiram na cabeça dos donos do negócio e de seus funcionários. Ao longo do tempo, alguns metadados de 
negócio foram registrados nos instrumentos de escrita que estavam disponíveis. Enquanto muitos dos metadados de negócio de hoje também existem na cabeça dos funcionários, uma quantidade significante deles tem sido capturados na forma de documentos, imagens ou ilustrações, e-mails, planilhas ou em bases de dados e ferramentas tecnológicas.

Ou seja, antes de serem identificados dessa forma, os metadados de negócio encontram-se nas empresas como informações tanto quantitativas como qualitativas dos processos de trabalho, e podem estar de forma não estruturada e aleatória ("na cabeça do gestor", ou seja, em forma de conhecimento tácito, em conteúdos de documentos etc) em diversos suportes (documentos, imagens, e-mails, planilhas etc), de forma estruturada ou semiestruturada (planilhas, bases de dados, ferramentas tecnológicas etc). De qualquer forma, ainda que estruturados ou semi-estruturados, esses metadados estão dispersos pela instituição e não há gestão sobre eles.

Os metadados de negócio são úteis para os gestores e demais atores no dia a dia dos seus processos de trabalho, e, portanto, devem estar na linguagem desses atores. (Inmon; O'Neil; Fryman, 2008). "São os metadados de negócio que fornecem o contexto de negócio apropriado para o entendimento e análise dos dados e para a tomada de decisão" (Sarda, 2008, p.14, tradução nossa)."Metadados de negócio fornecem contexto ao dado no DW [datawarehouse], para que o significado do negócio seja claro quando é usado nos vários processos de trabalho, incluindo para tomada de decisão" (Hamzah; Sobey, 2012, p.449, tradução nossa).

De forma semelhante Ikematu (2001) afirma que metadados de negócio são a descrição de dados necessários pelos usuários de negócio, para entender o contexto do negócio e o significado dos dados.

Segundo Sherman (2006a), a gestão de metadados de negócio possibilita o sucesso e a sustentabilidade da gestão corporativa. Hüner, Otto e Österle (2011, p.336, tradução nossa) afirmam que:

Fundamentalmente, a execução tranquila e eficiente de um negócio é assegurada por metadados que descrevem estrutura de dados dos objetos de negócio (seus atributos e relacionamentos) e fornecem informação para o uso correto dos objetos de negócio nos processos de negócio. Metadados de alta qualidade (metadados atualizados, precisos e completos) ajudam a criar e manter um entendimento comum dos objetos de negócio de processos de negócio.

Metadados de negócio estão diretamente relacionados à interpretação dos dados e como isso afeta o negócio como um todo. O conhecimento necessário para a criação de metadados de negócio consistentes está espalhado entre os vários departamentos, divisões ou linhas de negócio, sendo necessária a colaboração dos especialistas de negócio (Hüner; Otto; Österle, 2011). Dessa forma, os metadados de negócio possuem importantes desafios em termos de escopo, abstração e estrutura devido a diversidade de informações que precisam ser capturadas e modeladas (Sarda, 2008).

Inmon, O'Neil e Fryman (2008) afirmam que metadados de negócio podem ser encontrados em qualquer lugar, como: (a) em relatórios; (b) telas; (c) jornais; (d) documentos; (e) contratos; (f) propostas; (g) declarações de trabalho; (h) cartas de entendimento; (i) extratos bancários; (j) planilhas; e, (k) software de aplicação, entre outros.

Segundo os autores: "Em qualquer lugar que tenha usuário do negócio, você poderá encontrar também metadados de negócio. Metadados de negócio fornecem aos funcionários o contexto e significado dos dados representados pelo computador, então ele poderá ser precisamente utilizado pela empresa" (Inmon; O'Neil; Fryman, 2008, p.13, tradução nossa). Exemplos de metadados de negócio extraídos de um documento não estruturado podem ser visualizados na Figura 1: 


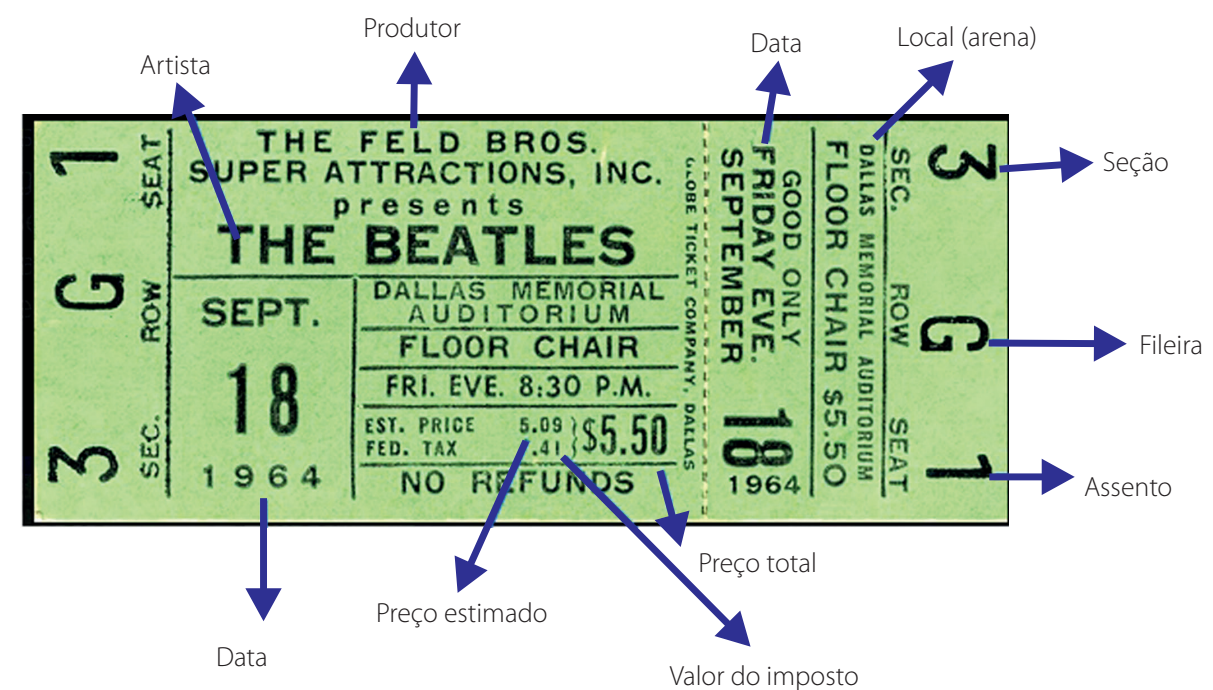

Figura 1. Metadados de negócio em ingresso de show

Fonte: Elaborado pelas autoras (2018).

Conforme ilustra a Figura 1, há várias informações não estruturadas sobre um negócio (no caso, um evento musical) que podem ser registradas e gerenciadas. São os metadados de negócio (artista, data, produtor, preço, local etc) extraídos do documento (ingresso).

Para ilustrar a diversidade dos metadados de negócio e confirmar a afirmativa de Inmon, O’Neil e Fryman (2008) sobre a possibilidade de se encontrar metadados de negócio em qualquer negócio, a Figura 2 exemplifica uma área de negócio inteiramente diferente do negócio da Figura 1, com um documento também bastante diverso contendo informação não-estruturada, em texto livre, e os metadados de negócio que podem ser encontrados:

Os metadados de negócio podem variar conforme a necessidade dos gestores do negócio. Por exemplo, caso o local do requerimento seja uma informação irrelevante para o negócio, este metadado não precisa ser registrado. A granularidade do metadado também depende das necessidades do negócio. Datas, por exemplo, podem gerar um único metadado de negócio "data" ou metadados distintos "dia", "mês"e "ano". O que vai definir essa granularidade é a especificação do negócio, informação que deverá ser obtida com gestores e atores do negócio (business person). Da mesma forma, os rótulos dos metadados podem ser diferentes dos utilizados nas Figuras 1 e 2, pois a linguagem deve ser de acordo com o contexto de negócio: deve-se fornecer metadados de negócio na linguagem do usuário (Sherman, 2006b).

Ressalta-se aqui que não há um conjunto padrão de metadados de negócio comum a todos os documentos e processos de trabalho, mas pode-se perceber algumas categorias básicas que se repetem e podem servir como base para a identificação desses metadados, como tempo, lugar e pessoa, ou ainda ser guiada pelas perguntas básicas "o que, quem, quando, porque e como". Sarda (2008) apresenta exemplo de categorias gerais, e, portanto, aplicável à maioria dos negócios, de metadados de negócio com base na estrutura de arquitetura corporativa de Zachman (Zachman Framework). São elas: funções, elementos organizacionais, objetivo, entidades de negócio, processos, eventos externos, medidas, avaliações, ações e conceitos de negócios.

Sherman (2006a) ressalta a confusão conceitual e terminológica existente na área: frequentemente, os metadados técnicos são confundidos com os metadados de negócio, e é o segundo que possibilita alavancar a gestão corporativa. Enquanto os metadados técnicos fornecem insumo para a área tecnológica, os metadados de negócio são elementos explicativos das funções dos dados para os gestores do negócio (Sherman, 2006a; Inmon; O'Neil; Fryman, 2008; Tao; Yu, 2014). 


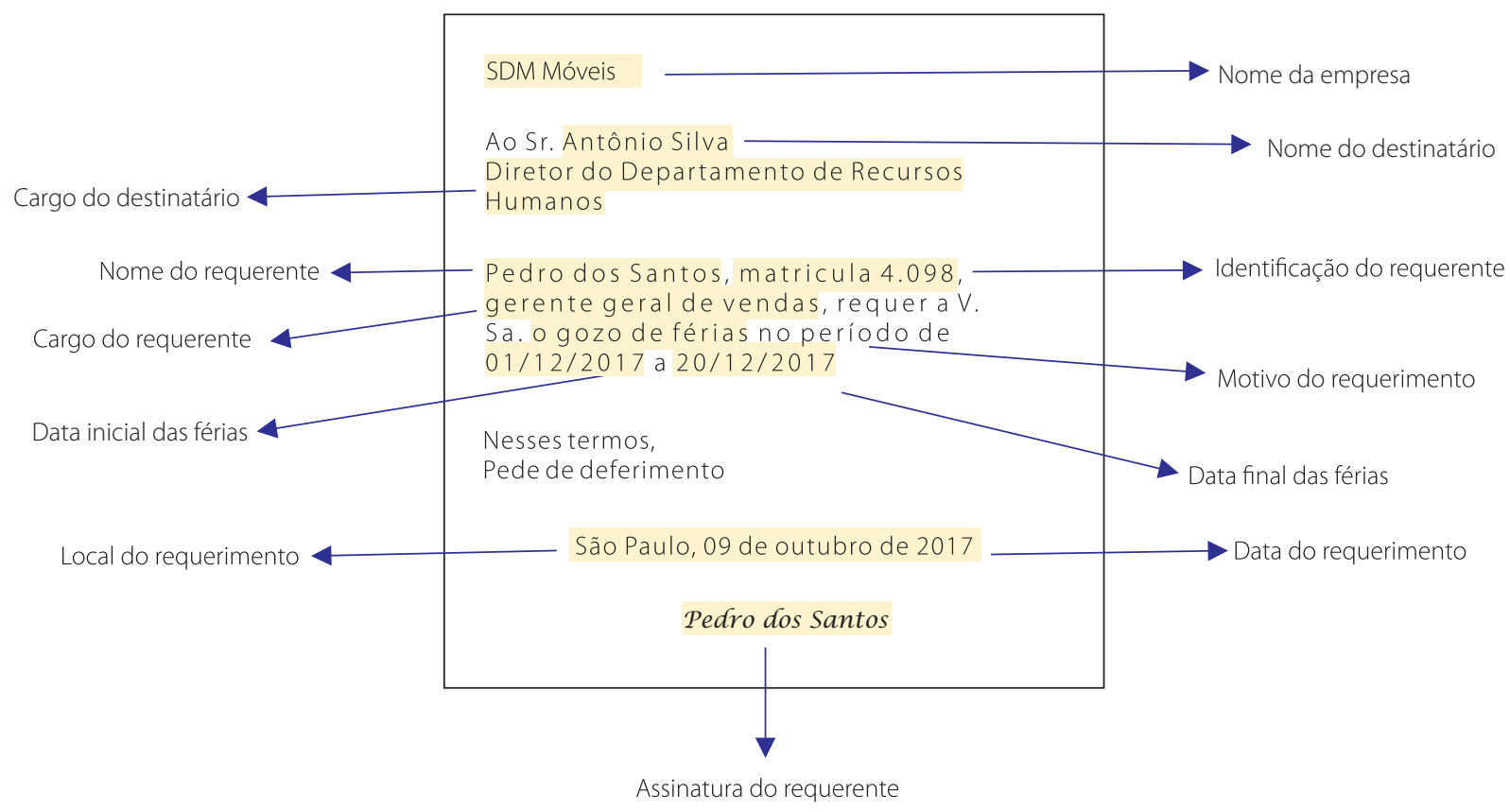

Figura 2. Metadados de negócio em documento administrativo.

Fonte: Elaborado pelas autoras (2018).

Como afirma Sherman (2006a), os metadados de negócio, após capturados nos processos da instituição, devem ser geridos. Para o autor, a gestão de metadados impulsiona os negócios. Marco (2006) compartilha dessa visão. Segundo ele, "A chave para sua empresa prosperar está em quão bem você reúne, preserva e dissemina conhecimento. Ambientes com gestão de metadados são críticos para reunir, preservar e disseminar conhecimento" (Marco, 2006, p.43, tradução nossa).

Além disso, como qualquer outro dado, os metadados de negócio mudam com o tempo (Inmon; O'Neil; Fryman, 2008; Sarda, 2008), já que as instituições mudam seus objetivos, missões, políticas, estruturas e processos. Mudanças no nível do negócio podem afetar os dados e metadados, e essa estrutura precisa ser acompanhada e atualizada. Para uma gestão efetiva, a construção de um repositório de metadados de negócio é aconselhada (Sherman, 2006a; Sarda, 2008; Hüner; Otto; Österle, 2011). Sarda (2008) enumera características importantes para repositórios de metadados de negócio. Entre elas, destaca-se a natureza temporal, ou seja, os metadados mudam ao longo do tempo devido a mudanças nos processos de negócio. Isso gera a necessidade de uma evolução integrada: mudanças nas políticas empresariais, objetivos, processos e regras resultam em novos requisitos para os sistemas. Com isso, há necessidade de revisão e atualização dos metadados de negócio e das aplicações e sistemas. Os atores do negócio devem estar a par dessas mudanças e o repositório de metadados deve registrar todas as versões dos metadados de negócio. O autor propõe a integração do repositório de metadados com o DatawareHouse (DW) da instituição, promovendo uma ligação entre metadados e dados da organização e facilitando a gestão integrada de processos, aplicações, metadados e dados.

\section{Metadados de negócio na Ciência da Informação}

A norma ISO 23081-1 (International Organization for Standardization, 2006) define metadados como informações estruturadas ou semiestruturadas que permitem criação, registro, classificação, acesso, preservação 
e disposição de registros ao longo do tempo e nos diferentes domínios, os quais representam áreas intelectuais e atividades sociais e organizacionais de grupos restritos, os quais compartilham valores e conhecimento. Metadados de negócio podem ser considerados nesta definição. O registro das informações do negócio de forma estruturada cria representações documentais, ou seja, registros, desses metadados na forma de recurso informacional. Essas representações podem conter, além da descrição do metadado de negócio, outros atributos relevantes para a gestão (do processo, do negócio, da tecnologia e da informação), ou seja, os metadados de negócio podem ser catalogados. Dessa forma, identifica-se uma atividade típica de Biblioteconomia e Ciência da Informação e acreditase que seus profissionais tenham a competência e os conhecimentos necessários para exercer funções relacionadas à gestão de metadados de negócio nas instituições.

Metadados de negócio são também elementos essenciais para a Arquitetura da Informação (Al), disciplina da Cl que abarca:

[...] uma metodologia que unifica métodos de organização, representação, acesso e disseminação de informação advindos da Biblioteconomia, com a estruturação espacial da Arquitetura, utilizando-se das tecnologias da informação e Comunicação para o planejamento de ambiente hipermídias informacionais digitais (Vidotti; Cusin; Corradi, 2008, p.175).

Ou seja, no âmbito da Cl, a Al atua nos processos de tratamento, armazenamento e acesso à informaç̧ão e possui como principal objeto os sistemas de informação construídos para atender às necessidades dos usuários (Robredo et al., 2008). Sistemas de informação os quais, conforme visto na seção 4, são responsáveis pela automatização de processos de trabalho, e, portanto, possuem vários metadados de negócio. De forma resumida, os processos de trabalho estão repletos de atividades e tarefas, as quais utiliza ou produz documentos (como os ilustrados nas Figuras 1 e 2). Esses documentos contêm metadados de negócio, que são identificados, extraídos e registrados para compor os sistemas de informação e permear a gestão da informação do processo. A representação, organização e estruturação desses metadados pode ser considerada uma metodologia de arquitetura de informação.

Os projetos de Al, que tem como base a tríade conteúdo, contexto e usuário (Rosenfeld; Morville; Arango, 2015), encontram-se em consonância com as atividades de captura e gestão de metadados de negócio - contexto dos dados sobre o negócio, na linguagem do usuário. O conteúdo são os valores em si: dados os quais esses metadados de negócio representam, e, portanto, os três pilares da Al são abarcados. Para Rosenfeld; Morville; Arango, (2015, p.110, tradução nossa): "A arquitetura da informação fornece talvez, o mais tangível retrato da missão, visão, valores, estratégia e cultura da sua instituição". Os metadados de negócio então entre os elementos que permitem esse retrato da instituição mencionado pelos autores.

Ainda no âmbito da Al, os metadados de negócio podem ser considerados também peças-chave que conectam as camadas de uma Arquitetura Corporativa, estrutura que une a missão e a estratégia do negócio de uma instituição a sua estratégia de TI, documentada por modelos arquiteturais (camadas) que atendem às necessidades atuais e futuras de usuários (Godinez et al., 2010). Os metadados de negócio extraídos dos processos de trabalho e sua descrição por meio de atributos fornecem insumo para as implementações tecnológicas: "Todos os sistemas de TI existem para acessar ou transmitir informação, e a Al liga os conjuntos de informação institucional aos processos de trabalho que precisam delas e aos sistemas de TI que as usam e as gerenciam" (Leganza, 2010, p.2, tradução nossa). Essa informação, ou seja, os metadados de negócio, num modelo de Arquitetura Corporativa, conectam arquitetura de processos, arquitetura da informação e arquitetura de tecnologia da informação da organização. Acredita-se que metadados de negócio, representados na camada de informação da Arquitetura Corporativa, possibilitam a implementação consistente de sistemas, como os dados e a informação são governados e compartilhados dentro da instituição e o que precisa ser feito para obter informações confiáveis relevantes ao negócio (Godinez et al., 2010). 
O repositório de metadados de negócio citado na seção 4 pode ser comparado ao catálogo de uma biblioteca ou serviço de informação. Constitui-se de um sistema que armazena representações dos metadados de negócio, juntamente com sua descrição e demais atributos pertinentes ao negócio, além de fornecer sua localização e elementos para sua gestão: quais os processos e sistemas utilizam determinado metadado e quem é seu gestor na empresa.

Metadados de negócio são efetivos também para a recuperação da informação, área nuclear da Cl. Tunnell (2013) aponta o uso de metadados de negócio como elementos para descrição de atributos específicos de recursos informacionais na área de Segurança Interna (Homeland Security). O autor explica que a área surgiu como disciplina recentemente e, por isso, não há uma forte tradição de pesquisa acadêmica e os repositórios de pesquisa especializados são limitados. Apesar disso, há muito material de interesse para a área em repositórios de psicologia e computação. Porém, a forma como os recursos estão descritos, por não terem como público alvo pesquisadores de Segurança Interna, dificulta a recuperação da informação por estes pesquisadores: "Um dilema resultante é que ser muito específico como a terminologia de segurança interna pode resultar em perda de material relevante, mas ser muito genérico resulta numa quantidade enorme de resultados" (Tunnel, 2013, p.39, tradução nossa). Como solução, o autor propõe uma nova abordagem para desenvolvimento de padrão para representação e recuperação da informação de segurança interna:

A solução de metadados para informação sobre segurança interna não requer um padrão completamente novo. Metadados de negócio fornecem contexto e significado aos dados que são representados por um computador e esse é o tipo de metadado importante para os pesquisadores de segurança interna. [...] Um padrão como o Dublin Core pode ser usado para descrição genérica do recurso e metadados de negócio para atributos específicos de segurança interna. (Tunnel, 2013, p.41, tradução nossa).

Outra característica do metadado de negócio que é central na Cl é a preocupação com o usuário. Sherman (2006b) afirma que os metadados de negócio devem estar na linguagem do usuário (businessperson), caso contrário "[...] os chamados metadados de negócios são lançados para os usuários "reais" do negócio - e eles não sabem o que fazer com ele. Eles ficam frustrados e rotulam o projeto de metadados um fracasso." O foco nas necessidades de informação do usuário é, portanto, essencial em um projeto de metadados de negócio:

Você não conhece um usuário do negócio até que conheça suas necessidades. Isso significa que você terá que falar com eles... e ouvi-los [...]. Isso significa que você precisa falar na linguagem deles. Você pode precisar de um intérprete para traduzir o que você está perguntando e o que eles estão respondendo. (Sherman, 2006b, p.40)

Essa preocupação com o usuário representa uma das bases da Cl, explicitada nas leis da Biblioteconomia enumeradas por Ranganathan em 1931, nos estudos de usuários e nos paradigmas cognitivo e social da $\mathrm{Cl}$.

Acredita-se que, apesar de já ser utilizado em outras áreas do conhecimento, o conceito de metadados de negócio deve ser abarcado nos estudos de $\mathrm{Cl}$ e que seus profissionais têm muito a contribuir na aplicação do mesmo em pesquisas teóricas e aplicadas, pois, conforme visto, há várias inter-relações possíveis a partir do olhar da $\mathrm{Cl}$.

Santos e Vidotti (2009, p.5) afirmam que: "Transformar a imensa massa de dados operacionais disponíveis diariamente em informações consistentes que permitam a tomada de decisões e agreguem valor às atividades e 
aos negócios é um dos desafios da Ciência da Informação". Acredita-se que os metadados de negócio possam ser considerados elementos importantes que a Ciência da Informação poderá utilizar para lidar com este desafio.

\section{Considerações Finais}

Os metadados são elementos fundamentais na Ciência da Informação e existem desde os primeiros registros de informação. Com as tecnologias de informação e comunicação e principalmente com o surgimento da internet e dos ambientes informacionais digitais, seu estudo e aplicações tornaram-se um grande foco da área de Cl. Verifica-se um crescente número de pesquisas sobre metadados, com suas diferentes tipologias, características e aplicações a partir dos anos 2000.

Apesar disso, não foram encontrados estudos brasileiros sobre metadados de negócio e suas aplicações nessa área. A partir da presente pesquisa, foram observadas grandes possibilidades para a utilização dessa tipologia de metadados na $\mathrm{Cl}$, concluindo-se que este conceito pode e deve ser inserido na área, principalmente nos estudos relacionados à Arquitetura da Informação, Sistemas de Informação e Recuperação da Informação.

Metadados de negócio estão presentes em todos os processos de trabalho das instituições e sua representação permite um nível de gestão que, segundo especialistas, pode impulsionar o negócio. A extração, registro e gestão desses metadados, com a construção de um repositório institucional de metadados, constituemse em ações importantes para as instituições. O desenvolvimento de sistemas de informação com base em projetos de Arquitetura da Informação que leve em conta os metadados de negócio permite uma automação efetiva do processo de trabalho, além do controle e da gestão da informação do negócio.

A partir da inserção desse tipo de metadado nos estudos de Cl no Brasil, surgem várias possibilidades de pesquisa, como estudos sobre a descrição de metadados de negócio, sobre a construção de um repositório de metadados de negócio, pesquisas sobre a visão dos usuários dos metadados de negócio, gestão da informação com base em metadados de negócio, além de estudos de caso de aplicação de metadados de negócio para desenvolvimento de sistemas de informação e gerenciamento da informação institucional. Alguns desses temas estão sendo pesquisados e devem complementar este artigo em publicações futuras.

\section{Colaboradores}

M.B. Brandt concepção e desenho, análise e interpretação dos dados. S.A.B.G. Vidotti revisão e aprovação da versão final do artigo.

\section{Referências}

Alves, R.C.V. Web Semântica: uma análise focada no uso de metadados. 2005. 180f. Dissertação (Mestrado em Ciência da Informação) - Universidade Estadual Paulista Júlio de Mesquita Filho, Marília, 2005.

Castro, F.F.; Santos, P.L.V.A.C. Os metadados como instrumentos tecnológicos na padronização e potencialização dos recursos informacionais no âmbito das bibliotecas digitais na era da web semântica. Informação e Sociedade: Estudos, v.17, n.2, p.13-19, 2007. Disponível em: <http://www.brapci.ufpr. br/brapci/v/a/7614>. Acesso em: 3 nov. 2017.

Gilliland, A.J. Setting the stage. In: Baca, M. Introduction to metadata. 3rd. ed. Los Angeles: Getty Publications, 2016.
Available from: <http://www.getty.edu/publications/intrometa data/setting-the-stage/>. Cited: Nov. 3, 2017.

Godinez, M. et al. The art of enterprise information architeture. Boston: IBM Press, 2010.

Hamzah, M.; Sobey, A. The use of business metadata to support decision-making processes. International Journal of Innovation, Management and Technology, v.3, n.5, p.449-451, 2012.

Hüner, K.M.; Otto, B.; Österle, H. Collaborative management of business metadata. International Journal of Information Management, v.31, n.4, p.366-373, 2011. 
Ikematu, R.S. Gestão de metadados: sua evolução na tecnologia da informação. DataGramaZero, v.2 n.6, p.1-5, 2001.

Inmon, W.H.;O'Neil, B.; Fryman, L. Business metadata: Capturing enterprise knowledge. Boston: Morgan Kaufmann, 2008. p.13.

International Organization for Standardization. ISO 23081-1: Information and documentation - Records management processes - Metadata for records, part 1: Principles. Geneva: ISO, 2006.

Leganza, G. Topic overview: Information architecture. Cambridge: Forrester Research, 2010. p.2.

Marco, D. Managing metadata for the business, part 1. DM Review, v.16, n.2, p.42-43, 2006.

National Information Standards Organization. Understanding metadata. Bethesda: NISO Press, 2004. Available from: <www. niso.org/publications/press/UnderstandingMetadata.pdf>. Cited: Nov. 3, 2017.

Robredo, J. et al. Reflexões sobre fundamentos da arquitetura da informação. In: Encontro Nacional de Pesquisa em Ciência da Informação, 9., 2008, São Paulo. Diversidade cultural e políticas de informação. São Paulo: Edusp, 2008.

Rosenfeld, L.; Morville, P.; Arango, J. Information architecture: For the web and beyond. 4th. ed. Boston: O'Reilly, 2015. p.110.

Ruhle, S.; Baker, T.; Johnston, P. User guide. 2011. Available from: $<$ https://github.com/dcmi/archive/blob/master/mediawiki_ wiki/User_Guide.md\#What_is_Metadata.3F>. Cited: Nov. 1, 2017.
Santos, P.L.V.A.C.; Vidotti, S.A.B.G. Perspectivismo e tecnologias de informação e comunicação: acréscimos à Ciência da Informação? DataGramaZero, v.10, n.3, p.1-10, 2009.

Sarda, N.L. Structuring business metadata in data warehouse systems for effective business support. The Computing Research Repository, cs.DB/0110020, p.2-16, 2001.

Sherman, R. Align metadata and business initiatives. DM Review, v.16, n.1, p.50, 2006a.

Sherman, R. Clear communication: The foundation for successful business metadata projects. DM Review, v.16, n.2, p.40, 2006b.

Tao, J.; Yu, J.L. Study on e-government and its decision support system. Applied Mechanics and Materials, v.635-637, p.1738-1741, 2014.

Taylor, A.G. The organization of the information. Westport: Libraries Unlimited, 2003. p.139.

Tunnell, H.D. Homeland security information representation: A case for standardization. Journal of Homeland Security Education, v.2, n.1, p.36-43, 2013.

Vidotti, S.A.B.G.; Cusin, C.A.; Corradi, J.A.M. Acessibilidade digital sob o prisma da Arquitetura da Informação. In: Guimarães, J.A.C.; Fujita, M.S.L. Ensino e pesquisa em Biblioteconomia no Brasil: a emergência de um novo olhar. São Paulo: Cultura Acadêmica, 2008.

Zeng, M.L.; Qin, J. Metadata. New York: Neal-Schuman Publishers, 2008. p.7. 